\title{
The meaning of forest conservation
}

Conservation in the truest and most commonly accepted meaning of the word has always been recognised as basic to the practice of sustainedyield forestry. For the 50 years of its existence the New Zealand Forest Service has considered that its policies have been fundamentally conservationist in philosophy and has assumed that they have been accepted by the public as such. Some recent events have led the Service to question the validity of the latter assumption, and indeed to question exactly what is meant by a policy of forest conservation.

A notable phenomenon of recent years has been the rapidly growing public concern about the quality of the environment in which man lives, a concern which has made itself felt simultaneously on both sides of the Atlantic and in both hemispheres. New Zealand has shared this worldwide manifestation of public conscience, whose catchwords have been conservation and pollution. Too often both have been used with too many shades of meaning, too many emotive overtones, and too few precise definitions. The word conservation itself tends to beg the question: What is being conserved and for what purpose?

This has led the Forest Service not only to examine its concept of what forest conservation really means, but to review its past actions in the conservation field as well as its conservation image in the eyes of the public. This last has become all the more urgent because of the growing criticism by some sectors of the public, including an influential scientific group, of the policy of replacing cut-over, derelict, or otherwise unused and unproductive native forests with what should be multipurpose production forests with much greater social and amenity values than the originals. This policy has been considered "anti-conservation", and indeed vandalism, instead of true forest conservation in the creative and dynamic sense of the word.

Our examination of Forest Service conservation philosophy has indicated that as foresters we use the term conservation in three distinct ways:

- When we talk of conserving native forests we really mean a deliberate rationing of the cut so that the use of a dwindling and non-renewable resource will be spread over a long rather than a relatively short period. This type of conservation, important though it is, has nothing to do with sustained yield and is not dynamic in concept.

- Likewise the second meaning of conservation reflects a philosophy of preservation by locking up - also a static concept. Nevertheless, it is entirely valid in two contexts:

In the maintenance, with as little human interference as is possible, of primitive or wilderness areas in some of the larger virgin indigenous State forests.

In the reservation and maintenance, again with the minimum of human interference, of forest sanctuaries or strict scientific reserves. These are designed to preserve examples of individual species, of forest associations, or of particular wildlife habitats; because of their scientific and ecological values they constitute an important though specialised facet of forest conservation.

- The most important type of forest conservation, however, is the dynamic one; it consists of the deliberate and planned manipulation of forests in such a manner that the many and varied benefits which forests can confer on mankind are maintained unimpaired and are indeed enhanced. This is conservation in the sense of the widely accepted definition: "preservation through wise use". It implies firstly the conservation in a healthy and productive state of forest soils, for no forests can flourish without continued soil fertility and an undiminished rooting medium. Likewise it implies the maintenance in perpetuity of all the particular products and benefits, direct and indirect, for which State forest land is being managed. This idea of sustained yield in perpetuity is applicable equally to:

Production of wood and other products for commercial use,

Water and soil conservation,

Preservation of scenery, Continued provision of recreational facilities, and Maintenance of wildlife habitats and scientific values.

The conflict, which all resources administrators must face, but which is not insoluble, is how to apply the principles of dynamic conservation in forests being managed for a multiplicity of purposes so that they are put to the most socially desirable productive uses but still maintain intact their protection, scientific, and scenic values. This is the challenge which generations of foresters have had to face in the past; in years to come, with a well-informed a nd conservationminded public looking more critically than ever before at what is done, there will be even greater calls on the knowledge and wisdom of those administering State, forest land.

From the Report of the Director-general of Forests for the year ended 31 March 1970, New Zeland Forest Service. 